\title{
PROGRAM PENGADAAN DAN PEMASANGAN LAMPU PENERANGAN JALAN UMUM DI PONDOK SUKATANI PERMAI, KELURAHAN SUKATANI, KECAMATAN RAJEG, KABUPATEN TANGERANG
}

\author{
Awaluddin Saputra ${ }^{1)}$, Jan Setiawan ${ }^{2)}$, Anto Carmanto ${ }^{3)}$, Ferdi \\ Sanofel $^{4)}$, Nurkahfi Irwansyah ${ }^{5)}$, Haerul Mubarok ${ }^{6)}$, Arief \\ Hidayattulloh $^{7)}$, Mochammad Fahroni ${ }^{8)}$, Rahmat Fajrin'), Jenal \\ Abidin ${ }^{10)}$ \\ 1,2,3,4,5,6,7,8,9,10 Program Studi Teknik Elektro, Fakultas Teknik, Universitas Pamulang
}

\begin{abstract}
Abstrak
Penerangan merupakan salah satu kebutuhan dasar masyarakat saat ini. Setiap tempat yang dihuni masyarakat pasti selalu ingin memiliki penerangan yang cukup. Hal ini karena setiap aktivitas masyarakat, baik didalam maupun diluar ruangan, baik siang terlebih di malam hari pasti membutuhkan penerangan. Begitu juga di jalan-jalan di lingkungan tempat masyarakat tinggal, sangat membutuhkan penerangan yang cukup. Karena penerangan di jalan sangat erat kaitannya dengan keamanan dan keselamatan masyarakat. Tidak semua masyarakat memiliki akses penerangan yang cukup, terutama penerangan di jalan umum tempat masyarakat tinggal. Salah satunya di jalan umum Pondok Sukatani Permai yang berada di wilayah Rajeg, Tangerang. Setelah melalui beberapa survei dan wawancara kepada masyarakat di daerah sekitar, ditemui kendala, minimnya penerangan di jalan umum/jalan boulevard perumahan yang dikeluhkan oleh warga yang tinggal di lingkungan RT 01/02 dan RT 04/02. Berdasarkan hasil survei tersebut, Universitas Pamulang mengadakan Pengabdian Kepada Masyarakat yang bertujuan untuk mengembangkan ilmu dan memberikan manfaat kepada masyarakat. Pengabdian Kepada Masyarakat atau PKM yang dilakukan dengan tema "Program Pengadaan Dan Pemasangan Lampu Penerangan Jalan Umum Di Pondok Sukatani Permai, Kelurahan Sukatani, Kecamatan Rajeg, Kabupaten Tangerang". Program ini dilaksanakan oleh dosen dan mahasiswa dengan tujuan untuk mengaplikasikan ilmu teknik elektro yang sudah dipelajari di kelas dan memberikan manfaat kepada masyarakat dengan meningkatnya penerangan jalan di lingkungan sekitar masyarakat tinggal.
\end{abstract}

Kata kunci: Lampu Penerangan Jalan, Keamanan, Pd. Sukatani Permai

\begin{abstract}
Lighting is one of the basic needs society right now. Every place inhabited by people always wants to have sufficient lighting. This is because every people's activity, both inside and outside of the room, both during the day and especially at night, definitely requires lighting. Likewise, streets in the neighborhood where people live, really need adequate lighting. Because street lighting is closely related to public's safety and security. Not all people have access to adequate lighting, especially lighting on public roads where people live. One of them is on the Pondok Sukatani Permai public street in the Rajeg area, Tangerang. After going through several surveys and interviews with people in the surrounding area, there was problem. The problem is lack of lighting on publicstreet that people living in the neighborhoods of RT 01/02 and RT 04/02. Based on the results of the surveys, Pamulang University held community service which aims to develop
\end{abstract}


knowledge and provide benefits to the community. Community Service or PKM carried out with the theme "Procurement and Installation of Street Lighting Programs at Pondok Sukatani Permai, Sukatani Village, Rajeg District, Tangerang Regency". This program is carried out by lecturers and students with the aim of applying the electrical engineering knowledge that has been learned in the class and providing benefits to the community by increasing street lighting in the neighborhoods where the people live.

Keywords: Street lighting, security, Pd. Sukatani Permai

Correspondence author: Awaluddin Saputra, dosen00332@unpam.ac.id, South Tangerang, and Indonesia

\section{PENDAHULUAN}

\subsection{Analisis Situasi Permasalahan}

Penerangan jalan umum merupakan salah satu hal penting karena berkaitan dengan keamanan dan keselamatan pengguna jalan, terutama di malam hari yang membutuhkan penerangan secara baik. Minimnya penerangan di jalan, dapat berdampak berbahaya untuk masyarakat, misalkan meningkatkan resiko kecelakaan di jalan hingga meningkatkan angka kriminalitas di jalan.

Dalam pengadaan dan pemasangan lampu penerangan jalan, ada dasar perencanaan yang harus dibuat dengan mempertimbangkan beberapa kriteria yang digunakan yaitu:

1). Volume lalu-lintas, baik kendaraan maupun lingkungan yang bersinggungan seperti pejalan kaki, pengayuh sepeda, dll;

2). Tipikal potongan melintang jalan, situasi (lay-out) jalan dan persimpangan jalan;

3). Geometri jalan, seperti alinyemen horisontal, alinyemen vertikal, dll;

4). Tekstur perkerasan dan jenis perkerasan yang mempengaruhi pantulan cahaya lampu penerangan;

5). Pemilihan jenis dan kualitas sumber cahaya/lampu, data fotometrik lampu dan lokasi sumber listrik;

6). Tingkat kebutuhan, biaya operasi, biaya pemeliharaan, dan lain-lain, agar perencanaan sistem lampu penerangan efektif dan ekonomis;

7). Rencana jangka panjang pengembangan jalan dan pengembangan daerah sekitarnya;

8). Data kecelakaan dan kerawanan di lokasi.

Selain itu, beberapa tempat yang memerlukan perhatian khusus dalam perencanaan penerangan jalan antara lain sebagai berikut:

1). Lebar ruang milik jalan yang bervariasi dalam satu ruas jalan;

2). Tempat-tempat dimana kondisi lengkung horisontal (tikungan) tajam;

3). Tempat yang luas seperti persimpangan, interchange, tempat parkir, dll;

4). Jalan-jalan berpohon;

5). Jalan-jalan dengan lebar median yang sempit, terutama untuk pemasangan lampu di bagian median;

6). Jembatan sempit/panjang, jalan layang dan jalan bawah tanah (terowongan); 
Program Pengadaan dan Pemasangan Lampu Penerangan Jalan Umum di Pondok Sukatani Permai,

7). Tempat-tempat lain dimana lingkungan jalan banyak berinterferensi dengan jalannya.

Terkait dengan minimnya lalmpu penerangan jalan di jalan boulevard perumahan Pondok Sukatani Permai RT 01/02 dan RT 04/02, diperlukan perencanaan yang baik sebelum melakukan pengadaan dan pemasangan lampu penerangan jalan. Hal ini terkait dengan rencana anggaran yang dikeluarkan, jumlah titik pemasangan lampu penerangan jalan, jenis-jenis komponen lampu penerangan dan spesifikasi tiang lampu penerangan yang akan digunakan. Karena dengan perencanaan yang baik diharapkan hasil pekerjaan dapat bekerja dengan baik dan awet dari segi umur pemakaian.

Dari uraian penjelasan dan perencaan diatas, kami selaku dosen dan mahasiswa dari Teknik Elektro UNPAM mengadakan PKM yang bertujuan untuk membantu warga yang membutuhkan penerangan jalan serta memberikan contoh instalasi lampu penerangan jalan yang baik sesuai dengan standar yang ada. Kegiatan PKM ini didukung oleh Universitas Pamulang sebagai bentuk Tri Dharma Perguruan Tinggi yang akan dilaksanakan secara berkelanjutan di setiap semester.

\section{METODE PELAKSANAAN}

\subsection{Kerangka Pemecahan Masalah}

Untuk memberikan solusi terhadap permasalahan diatas, maka diperlukan beberapa tahapan-tahapan sebagai berikut:

1). Menganalisa kebutuhan yang terkait dengan permasalahan yang dihadapi masyarakat. Seperti berapa kebutuhan titik lampu yang akan dipasang karena akan terkait dengan anggaran, bahan, material dan alat yang akan digunakan dalama pengadaan dan pemasangan lampu jalan.

2). Membuat design sistem instalasi lampu penerangan jalan umum. Hal ini terkait dengan wiring/rangkaian instalasi lampu, termasuk titik pemasangan lampu, panjang kabel dan komponen yang akan digunakan sudah dijelaskan lengkap di wiring. Selain itu terkait juga dengan tiang-tiang lampu yang akan dipasang meliputi tinggi tiang dan jarak pemasangan antar tiang lampu penerangan.

3). Penyusunan bahan dan peralatan. Hal ini meliputi pembuatan tiang-tiang lampu jalanan, persiapan bahan-bahan seperti komponen yang akan dipasang dan persiapan alat-alat yang akan digunakan pada saat pelaksanaan pemasangan lampu jalan.

4). Pelaksanaan pemasangan lampu jalanan. Meliputi pemasangan tiang-tiang, pemasangan lampu jalanan, pemasangan kabel antar tiang lampu penerangan. Kemudian melakukan pengetesan untuk memastikan lampu bekerja dengan baik.

\subsection{Realisasi Pemecahan Masalah}

Persiapan pelaksanaan diawali dengan pertemuan untuk menetapkan beberapa hal seperti jenis kegiatan PKM, topik PKM, lokasi, dan waktu. Setelah itu, berdasarkan pertemuan berikutnya ditetapkan susunan 
acara, daftar peralatan dan bahan, pembuatan alat peraga dan anggaran biaya. Sasaran kegiatan PKM ini adalah masyarakat Perumahan Pondok Sukatani Permai RT 01/02 dan RT 04/02, Kel. Sukatani, Kec. Rajeg, Kab. Tangerang. Sasaran utamanya adalah warga yang beraktivitas lalu-lalang disekitar jalan boulevard yang menghadapi masalah minimnya lampu penerangan jalan di sekitar jalan boulevard tersebut.

Oleh karena itu untuk kelancaran kegiatan PKM, Prodi Teknik Elektro UNPAM bekerjasama dengan ketua RT dan masyarakat di lingkungan RT 01/02 dan RT 04/02 Perumahan Pondok Sukatani Permai. Melalui kegiatan ini diharapkan masyarakat memiliki lampu penerangan jalan yang lebih baik baik sehingga meningkatkan keamanan dan kenyamanan masyarakat saat beraktivitas terutama di malam hari.

\subsection{Khalayak Sasaran}

Sasaran kegiatan adalah masyarakat perumahan Pondok Sukatani Permai RT 01/02 dan RT 04/02, Kel. Sukatani, Kec. Rajeg, Kab. Tangerang

\subsection{Tempat dan Waktu \\ Tempat Kegiatan}

Waktu Pelaksanaan

: Jalan Boulevard Perumahan Pondok Sukatani Permai, Kel. Sukatani, Kec. Rajeg, Kab. Tangerang

: $\quad$ Minggu, 26 Juli 2020 s/d Rabu, 29 Juli 2020

\subsection{Metode Kegiatan}

Metode yang digunakan dalam pengabdian masyarakat ini adalah melalui kegiatan:

1). Pembuatan design sistem instalasi lampu penerangan jalan umum.

2). Penyusunan bahan dan peralatan yang akan digunakan.

3). Implementasi pemasangan lampu penerangan jalan umum.

\section{HASIL DAN PEMBAHASAN}

Berikut ini adalah rangkaian acara PKM yang telah dilaksanakan:

Tabel 1 Rangkaian Acara Kegiatan PKM

\begin{tabular}{lll}
\hline \multicolumn{1}{c}{ Waktu } & \multicolumn{1}{c}{ Kegiatan } & \multicolumn{1}{c}{ Pembicara/pelaksanaan } \\
\hline Minggu, 26 Juli 2020 & $\begin{array}{l}\text { Koordinasi dan sosialisasi kegiatan PKM yang akan } \\
\text { dilaksanakan pada hari senin 27 Juli 2020 }\end{array}$ & $\begin{array}{l}\text { Ketua pelaksana PKM dan Ketua } \\
\text { RT }\end{array}$ \\
\hline $14.00-16.00$ & $\begin{array}{l}\text { Memindahkan bahan dan alat yang akan digunakan ke } \\
\text { balai RW }\end{array}$ & $\begin{array}{l}\text { Mahasiswa Teknik Elektro dan } \\
\text { Dosen Pembimbing }\end{array}$ \\
\hline Senin, 27 Juli 2020 & & \\
\hline $14.00-15.00$ & $\begin{array}{l}\text { Mahasiswa dan dosen sudah hadir untuk safety briefing } \\
\text { sebelum melaksanakan kegiatan PKM }\end{array}$ & $\begin{array}{l}\text { Mahasiswa Teknik Elektro dan } \\
\text { Dosen Pembimbing }\end{array}$ \\
\hline $15.00-16.00$ & Sambutan pembukaan PKM & $\begin{array}{l}\text { Ketua RT, Masyarakat setempat } \\
\text { dan Ketua Pelaksana PKM }\end{array}$ \\
\hline
\end{tabular}


Program Pengadaan dan Pemasangan Lampu Penerangan Jalan Umum di Pondok Sukatani Permai, KelurahanSukatani, Kecamatan Rajeg, Kabupaten Tangerang

\begin{tabular}{|c|c|c|}
\hline Waktu & Kegiatan & Pembicara/pelaksanaan \\
\hline $16.00-19.00$ & $\begin{array}{l}\text { Pembuatan tiang-tiang lampu penerangan jalan di balai } \\
\text { RW }\end{array}$ & 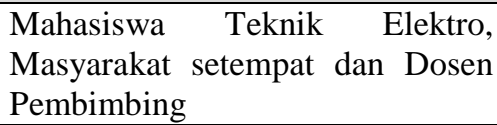 \\
\hline \multicolumn{3}{|c|}{ Selasa, 28 Juli 2020} \\
\hline $14.00-16.00$ & $\begin{array}{l}\text { Penggalian lubang untuk pemasangan tiang lampu } \\
\text { penerangan jalan }\end{array}$ & $\begin{array}{l}\text { Mahasiswa Teknik Elektro dan } \\
\text { Dosen Pembimbing }\end{array}$ \\
\hline $16.00-18.00$ & $\begin{array}{l}\text { Pengecoran dan pemasangan besi penyangga tiang } \\
\text { lampu penerangan jalan }\end{array}$ & $\begin{array}{l}\text { Mahasiswa Teknik Elektro dan } \\
\text { Dosen Pembimbing }\end{array}$ \\
\hline \multicolumn{3}{|c|}{ Rabu, 29 Juli 2020} \\
\hline $13.00-17.00$ & $\begin{array}{l}\text { Pemasangan lampu penerangan jalan pada tiang, } \\
\text { penyambungan kabel antar tiang dan pengetesan hasil } \\
\text { pemasangan }\end{array}$ & $\begin{array}{l}\text { Mahasiswa Teknik Elektro dan } \\
\text { Dosen Pembimbing }\end{array}$ \\
\hline $17.00-18.00$ & Acara penutupan dan do'a & $\begin{array}{l}\text { Ketua RT, Masyarakat setempat } \\
\text { dan Ketua Pelaksana PKM }\end{array}$ \\
\hline
\end{tabular}

\subsection{Persiapan PKM}

Pada tahap persiapan, dilakukan survey lapangan untuk melihat langsung titik-titik mana saja pada jalan yang memerlukan pemasangan lampu penerangan. Dari hasil survey tersebut, dilakukan pemasangan 4 titik tiang lampu penerangan jalan. Hal ini akan membantu dalam persiapan kebutuhan anggaran dan belanja untuk keperluan pelaksanaan PKM.

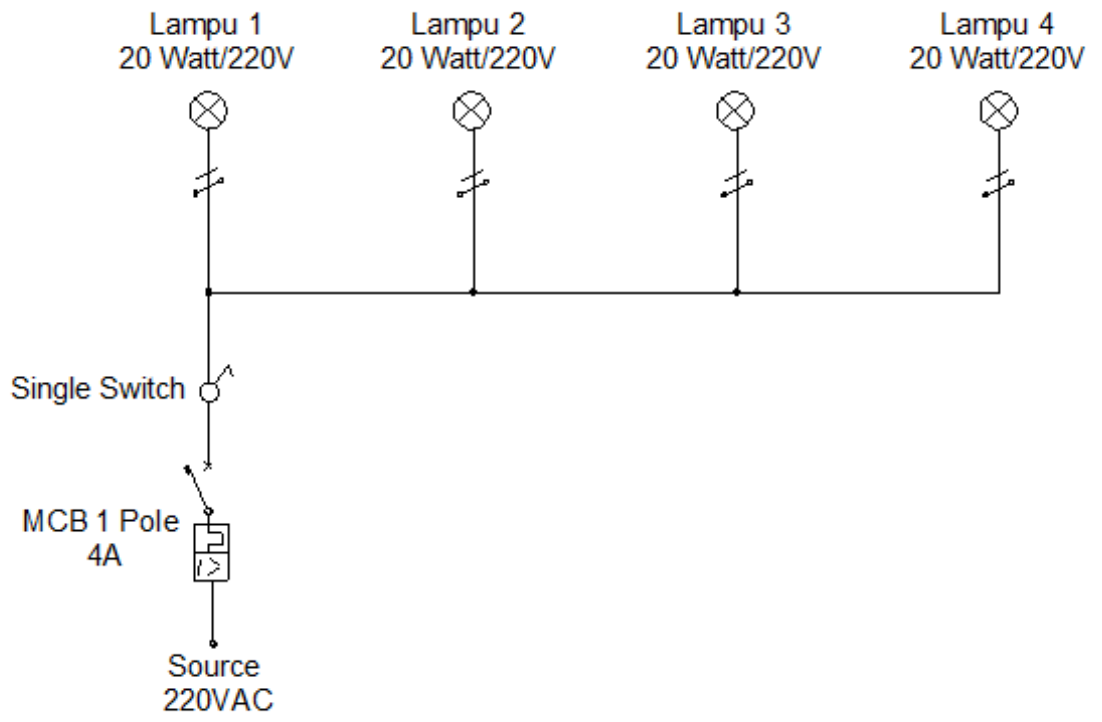

Gambar 1 Single Line Diagram Pemasangan Lampu Penerangan Jalan.

Pada gambar 1 merupakan single line diagram pemasangan lampu penerangan jalan yang sudah dibuat. Ada 4 titik pemasangan lampu penerangan jalan. Dengan tambahan saklar untuk mematikan dan menyalakan lampu. Mini Circuit Breaker (MCB) digunakan sebagai pengaman beban lebih pada instalasi lampu penerangan jalan. Selain komponen-komponen yang sudah disebutkan pada single line diagram, juga terdapat tambahan komponen-komponen pendukung seperti kap lampu, box MCB, pipa konduit dan clamp-nya. 


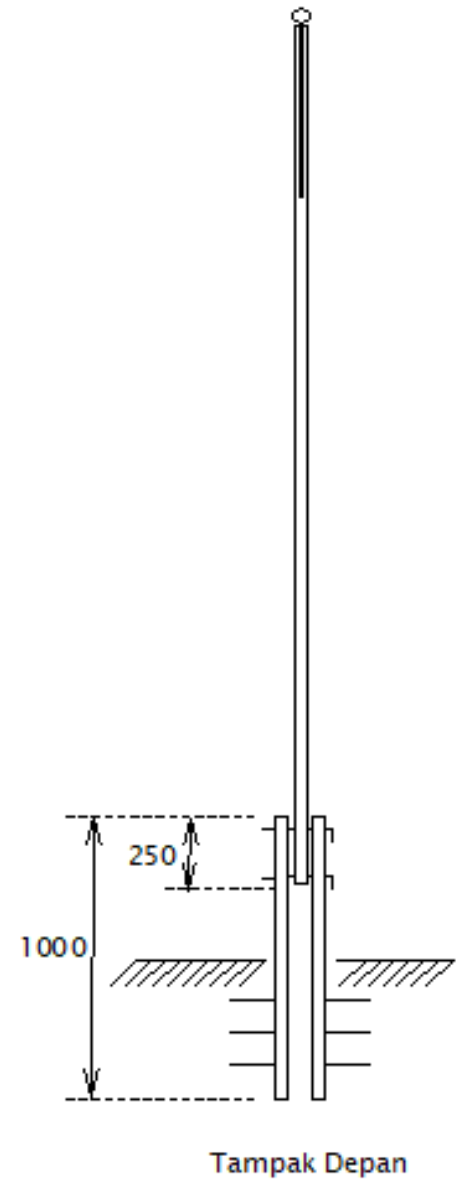

Gambar 2 Spesifikasi Tiang Lampu Penerangan Jalan

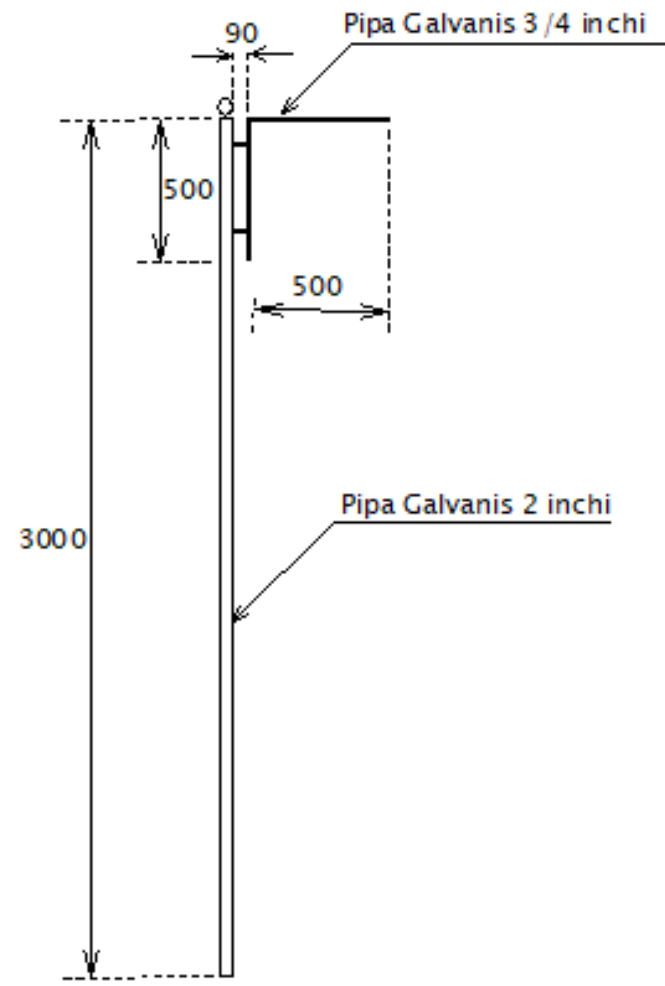

Tampak Samping

Pada gambar 2 merupakan spesfifikasi tiang lampu penerangan jalan. Spesifikasinya meliputi jenis besi yang digunakan pada tiang dan ukurannya. Tiang lampu penerangan menggunakan pipa galvanis karena tahan karat, awet saat digunakan dan kuat.

\subsection{Pelaksanaan PKM}

Pelaksanaan PKM dilaksanakan pada hari Minggu, 26 Juli 2020 s/d Rabu, 29 Juli 2020 di Jalan Boulevard Perumahan Pondok Sukatani Permai, Kel. Sukatani, Kec. Rajeg, Kab. Tangerang. Acara diawali dengan koordinasi dan sosialisasi kegiatan PKM, dilanjutkan dengan memindahkan bahan dan alat yang akan digunakan. Kemudian dilanjutkan safety briefing sebelum memulai pekerjaan dan pemberian sambutan pembukaan dari perwakilan program studi Teknik Elektro UNPAM, Bapak Awaluddin S selaku ketua pelaksana program PKM Teknik Elektro UNPAM beserta sambutan dari ketua RT setempat. Setelah pembukaan, acara dilanjutkan lagi dengan rangkaian acara PKM lainnya seperti tertera pada tabel 1 . 
Program Pengadaan dan Pemasangan Lampu Penerangan Jalan Umum di Pondok Sukatani Permai, KelurahanSukatani, Kecamatan Rajeg, Kabupaten Tangerang

| 150-154

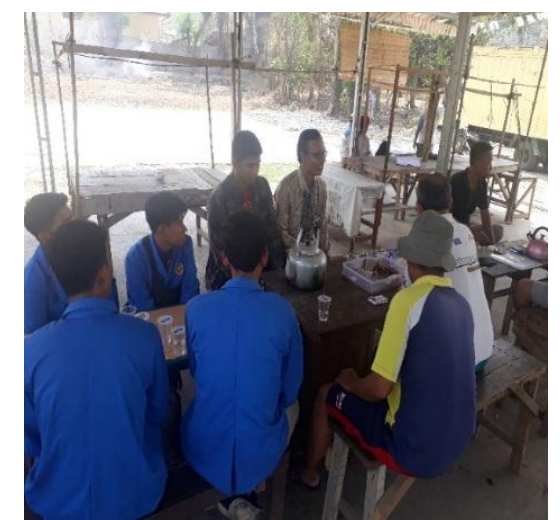

Gambar 3 Safety Briefing Sebelum Pelaksanaan PKM

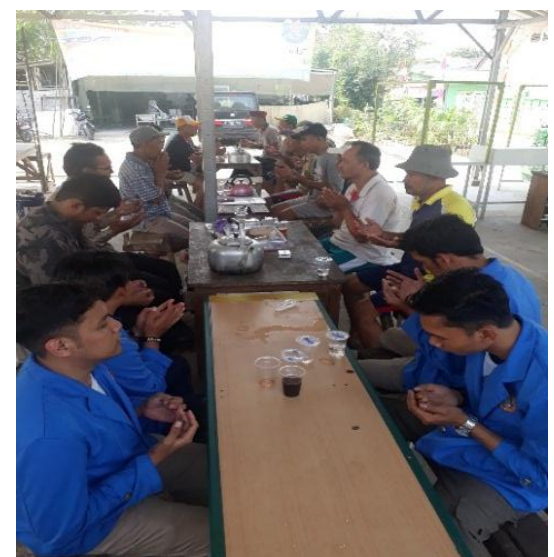

Gambar 4 Sambutan dan Doa Sebelum Pelaksanaan PKM

Dilaksanakan safety briefing sebelum pelaksanaan PKM. Safety briefing dilakukan untuk mengingatkan agar mahasiswa dan dosen selama proses pelaksanaan PKM tetap memperhatikan safety dengan bekerja mengikuti prosedur keselamatan dan menggunakan peralatan safety seperti safety helmet dan safety harness agar pekerjaan berjalan lancar dan selamat. Selanjutnya dilaksanakan sambutan pembukaan PKM oleh ketua pelaksana PKM dan ketua RT diikuti oleh masyarakat setempat, dosen dan mahasiswa. Tidak lupa diikuti doa bersama meminta kelancaran dan perlindungan agar pelaksanaan PKM berjalan lancar.

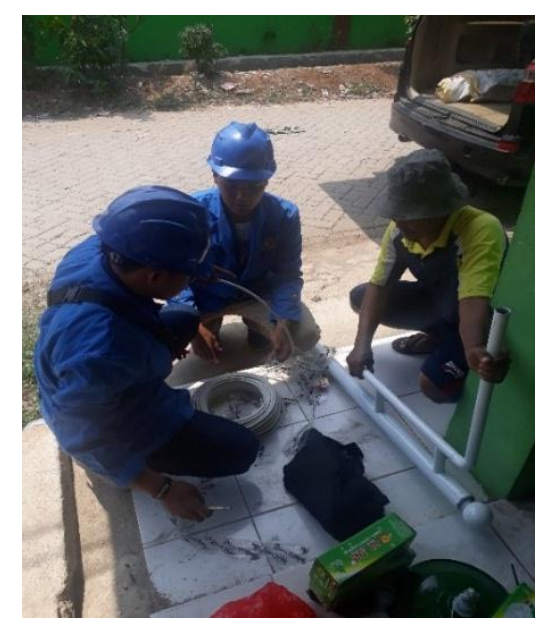

Gambar 5 Proses Pemasangan Kabel Tiang Lampu Penerangan. 


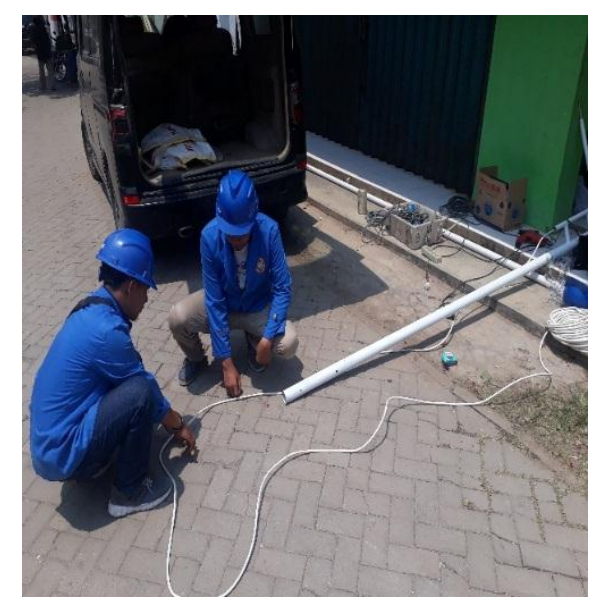

Gambar 6 Proses Pemasangan Kabel Tiang Lampu Penerangan.

Sebelum pemasangan kabel pada tiang lampu penerangan, harus dilakukan pengukuran terlebih dahulu jumlah kabel yang dibutuhkan agar sesuai dengan kebutuhan. Kabel yang digunakan yaitu kabel jenis NYM dengan ukuran 2 x 1,5 mm SNI. Pemilihan jenis kabel ini karena memiliki kualitas baik untuk instalasi penerangan dan diberikan tambahan instalasi pipa konduit pada kabel untuk melindungi instalasi kabel agar aman dan tidak mudah rusak jika terjadi gangguan dari luar seperti gigitan tikus. Dan juga apabila ada isolasi kabel yang terkelupas tidak tersentuh langsung oleh manusia.

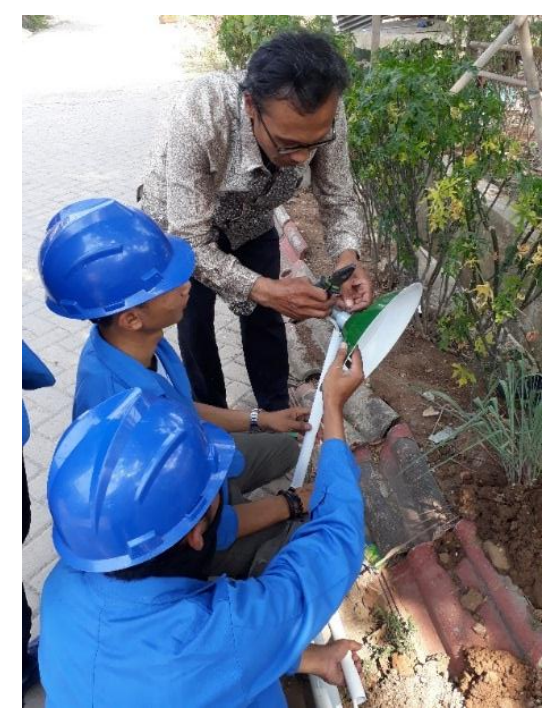

Gambar 7 Proses Pemasangan Lampu dan Kap Lampu Penerangan.

Lampu dipasang pada tiang menggunakan tambahan kap lampu. Kap lampu berfungsi untuk mencegah lampu basah akibat air hujan dan juga untuk membantu memfokuskan cahaya lampu penerangan. Untuk lampu yang digunakan yaitu lampu LED 20 watt. Pemilihan lampu jenis ini karena memiliki efisiensi tinggi, umur pemakaian panjang dan memiliki tingkat pencahayaan yang baik. Selama proses pengerjaan, selain ikut bekerja, dosen pembimbing juga selalu ikut mengawasi pelaksanaan proses pekerjaan agar hasil pekerjaan yang dilakukan baik dan benar sesuai dengan standar. 
Program Pengadaan dan Pemasangan Lampu Penerangan Jalan Umum di Pondok Sukatani Permai, KelurahanSukatani, Kecamatan Rajeg, Kabupaten Tangerang

| $152-154$

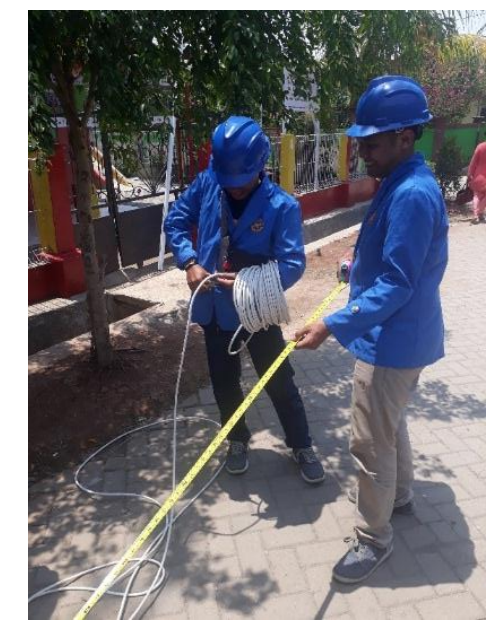

Gambar 8 Proses instalasi kabel antar tiang.

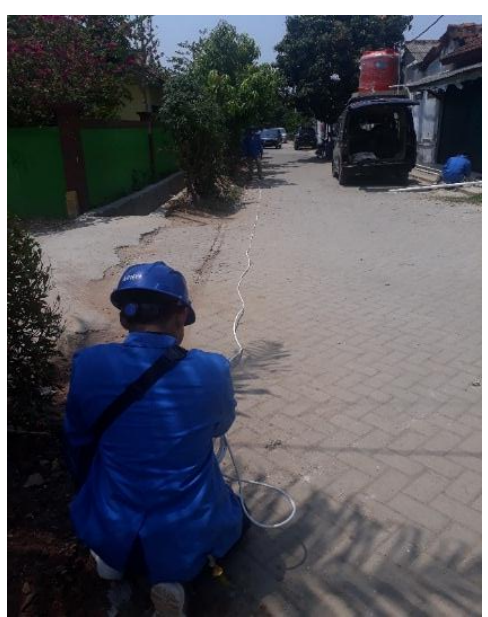

Gambar 9 Proses instalasi kabel antar tiang.

Seperti yang sudah dijelaskan sebelumnya, terdapat 4 titik pemasangan lampu yang berbeda-beda. Sehingga diperlukan instalasi kabel antar tiang agar terhubung tiang-tiang lampu penerangan terhubung ke sumber listrik secara paralel. Proses instalasi kabel antar tiang dilakukan pengukuran terlebih dahulu jumlah kabel yang dibutuhkan agar sesuai dengan kebutuhan.

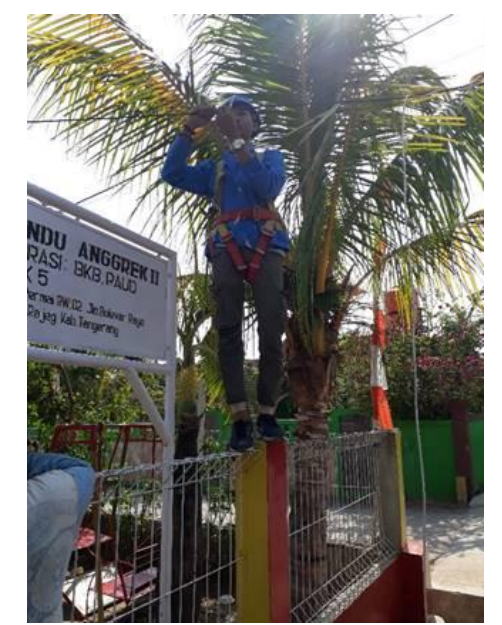

Gambar 10 Proses instalasi kabel antar tiang. 
Proses instalasi kabel antar tiang yang mengharuskan harus bekerja di ketinggian tertentu, selain memerlukan safety helmet juga memerlukan peralatan tambahan yaitu safety harness agar tetap aman saat bekerja di ketinggian.

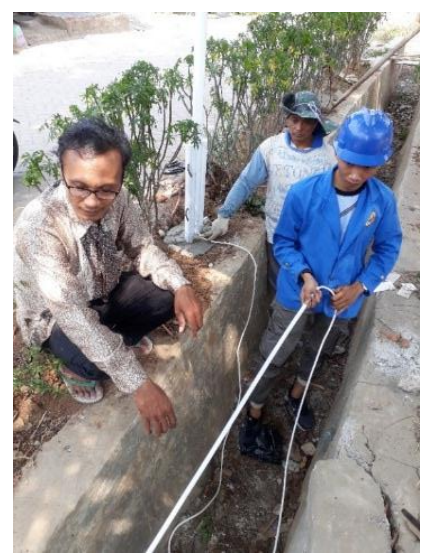

Gambar 11 Proses Pemasangan Pipa Konduit Pada Kabel.

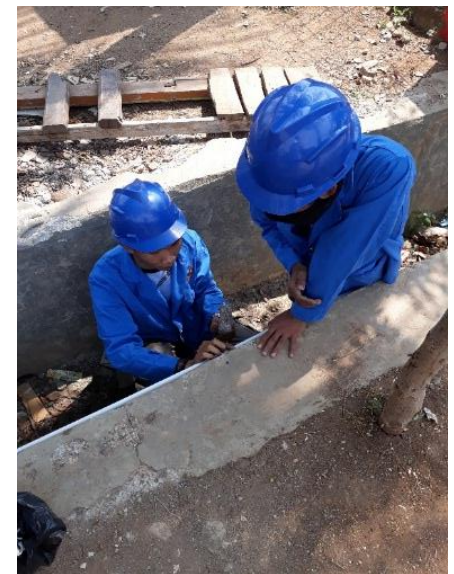

Gambar 12 Proses Pemasangan Pipa Konduit Pada Kabel.

Selain kabel pada tiang perlu yang dipasang pipa konduit, kabel instalasi antar tiang juga perlu dilakukan pemasangan pipa konduit agar kabel terlindung dan aman dari gangguan luar. Seperti yang terlihat pada gambar 4.11 proses pemasangan pipa konduit sedang dilakukan mahasiswa dengan pengawasan dosen.

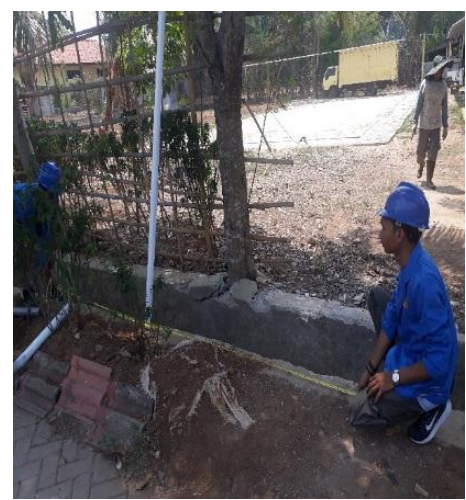

Gambar 13 Pemasangan Tiang Lampu Penerangan. 
Sebelum tiang lampu penerangan dapat dipasang, terlebih dahulu dibuat lubang galian pada titik dimana tiang lampu penerangan jalan akan dipasang. Lubang galian ini berfungsi sebagai tempat tiang penyangga lampu penerangan. Setelah lubang galian dibuat, tiang dapat dipasang pada lubang galian ini. Agar kuat, tiang penyangga ini kemudian dicor menggunakan pasir dan semen.

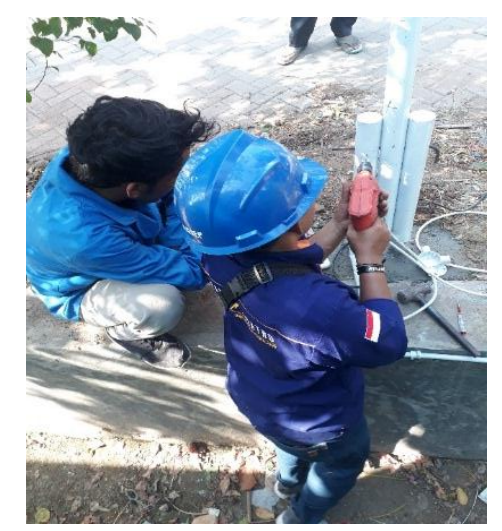

Gambar 14 Pemasangan Tiang Lampu Penerangan.

Pemasangan tiang lampu lampu penerangan dilakukan pada tiang penyangga. Tiang lampu penerangan dipasang pada tiang penyangga menggunakan pengunci berupa besi yang dapat dilepas/pasang untuk memudahkan saat perawatan dan perbaikan jika terjadi kerusakan.

\section{SIMPULAN}

Kesimpulan yang diperoleh dari pelaksanaan PKM ini adalah:

1). Kegiatan PKM yang berbentuk pengadaan dan pemasangan lampu penerangan jalan ini berjalan dengan sangat lancar.

2). Lampu penerangan jalan sebanyak 4 titik dengan tinggi tiang 3 meter dan menggunakan lampu LED 20 watt berhasil dibuat dan dapat bekerja dengan baik untuk menerangi jalan boulevard tempat titik lampu penerangan tersebut dipasang.

3). Kegiatan PKM ini disambut antusias oleh masyrakat sekitar terbukti dengan antusias besar masyarakat sekitar yang ikut serta membantu proses pelaksanaan kegiatan PKM.

\section{DAFTAR PUSTAKA}

Mansur. (2015). Analisis Kelistrikan Lampu Penerangan Jalan Umum (PJU) Kawasan Perkantoran Kabupaten Konawe Selatan. Kendari: FT Universitas Halu Oleo.

Standar Nasional Indonesia, SNI 7391. (2008). Spesifikasi Penerangan Jalan di Kawasan Perkotaan. Jakarta: Badan Standarisasi Nasional.

Syarifudin, Ilyas Achmad, Sirait, Bonar, Purwoharjono. (2015). Rancang Bangun Penataan Lampu Penerangan Jalan Umum Di Kota Sintang. Sintang: FT Universitas Tanjungpura. 